\title{
NIGHT-SHIFT WORK AND RISK OF COMPROMISED VISUAL ACUITY AMONG THE WORKERS IN AN ELECTRONICS MANUFACTURING COMPANY
}

\author{
YU-CHENG LIN ${ }^{1,2,3}$ and KUO-JUNG HO ${ }^{2}$ \\ ${ }^{1} \mathrm{Fu}$ Jen Catholic University, New Taipei City, Taiwan \\ School of Medicine \\ ${ }^{2}$ En Chu Kong Hospital, New Taipei City, Taiwan \\ Department of Occupational Medicine \\ ${ }^{3}$ Tao Yuan General Hospital, Tao Yuan City, Taiwan \\ Department of Occupational Medicine
}

\begin{abstract}
Objectives: To evaluate the association between night-shift work exposure and visual health, this cross-sectional study utilized visual acuity, a surrogate measure for visual function, as a parameter, and performed an analysis comparing visual acuity between daytime and nighttime employees in an electronics manufacturing company. Material and Methods: Data of personal histories, occupational records, physical examinations and blood tests was obtained from the electronic health records of workers. The total of 8280 workers including 3098 women and 5182 men, wearing their own daily used eyeglasses, were included in the final analysis. The mean age of the sample population was 34.7 years old (standard deviation $=5.4$ years). All workers were divided into 3 work categories - consistent daytime worker $(\mathrm{CDW})$, day-shift worker (DSW) and night-shift worker (NSW). The check-up results of glasses-corrected visual acuity (c-VA) were utilized to classify individuals as good $(\geq 1.2$, both eyes) and inadequate $(<0.8$, the better eye $) c-V A$. Results: Consistent daytime workers had the highest rate of good c-VA (42.5\% vs. $25.1 \%$ DSW and 21.1\% NSW, p $=0.047)$. Night-shift workers had the highest rate of inadequate c-VA (CDW, DSW and NSW: $2.6 \%, 6.2 \%$, and 7.6\%, p = 0.03) among all employees. After controlling for covariates, NSW were found at an increased risk for inadequate c-VA (adjusted odds ratio $\left(\mathrm{OR}_{\mathrm{a}}\right)=2.7$, 95\% confidence interval (CI): 2.0-3.6, vs. CDW), and less likely to have good c-VA (OR $=0.4,95 \% \mathrm{CI}$ : $0.4-0.5$, vs. CDW). Conclusions: Night-shift work is moderately associated with compromised visual acuity of employees in this electronics manufacturing company. Int J Occup Med Environ Health 2018;31(1):71-79
\end{abstract}

Key words:

Aging, Occupational health, Visual acuity, Electronics manufacturing industry, Health check-ups, Night-shift work

\section{INTRODUCTION}

Controlling the entry of light, eye plays an essential role in regulating circadian rhythm of the human body [1]. Similar to other organs in the human body [2], diurnal rhythms such as intraocular pressure fluctuations exist in human eyes [3].
Night jobs are associated with visual fatigue [4,5] and the diurnal inconsistency of intraocular pressure was found amongst night-shift workers [6]. Furthermore, shift work and disturbed sleep were already proposed as the risk factors for retinopathy $[7,8]$. Theoretically, a normal diurnal

Received: May 21, 2016. Accepted: November 9, 2016.

Corresponding author: Yu-Cheng Lin, En Chu Kong Hospital, Department of Occupational Medicine, Fuxing Road 399,237 New Taipei City, Taiwan (e-mail: gphinx@gmail.com). 
rhythm is important to the health of human eyes, however, visual functions among night-shift workers, whose diurnal rhythms differ from those of daytime workers, have rarely been investigated on a large scale.

In Taiwan, night-shift work is legislated as a health hazard in workplaces [9] and periodic health evaluations are compulsory to all employees [10]. This health data including visual acuity, a surrogate measure for visual function, provides a splendid basis for observational research to assess the associations with night work exposure on visual health among workers.

To evaluate the association between visual health and night-shift work, an unavoidable occupational exposure in the modern workplace, we conducted a large scale workplace-based survey to assess the differences of visual acuities between nighttime and daytime workers.

\section{MATERIAL AND METHODS}

\section{Study populations}

Employees in one electronics manufacturing company received periodic health check-ups to monitor general health conditions. The compulsory health check-up was performed in November 2013 by one qualified health check-up institution [10] in North Taiwan. The corrected visual acuity (c-VA), occupational, personal and health records of a total of 8280 workers including 3098 women and 5182 men, wearing their own daily used eyeglasses, were included in the final analysis.

\section{Study design and data collection}

This cross-sectional study analyzed secondary data obtained from existing health check-up records of employees. The Ethical Committee for Human Research at En Chu Kong Hospital, New Taipei City, Taiwan, approved the study protocol used in this work (ECKIRB1040501). The En Chu Kong Hospital Institutional Review Board waived the requirement for informed consents from the participants due to the retrospective and anonymous nature of this analysis.

\section{Demographic and biological measurements}

Health check-ups were performed in accordance with the standard procedures [10]. Anthropometric data of the physical examination records included measurements of waist circumferences and blood pressure. Waist circumferences were measured midway between the lowest rib and the superior border of the iliac crest. Sitting blood pressure was measured on the dominant arm using digital automatic sphygmomanometers. Participants were placed in a reclining position, and venous blood from an antecubital vein of the arm was taken for subsequent tests.

After at least an overnight $8 \mathrm{~h}$ fast, analyses of fasting glucose, triglyceride and high-density lipoprotein (HDL) cholesterol were conducted by autoanalyzers. Blood specimens were centrifuged immediately and shipped frozen in dry ice to the central clinical laboratory. Participants wore their own daily used eyeglasses during eye examination; visual acuity was obtained by well-trained and experienced nurses using table-top visual acuity instruments [11].

\section{Definitions}

Exposure

All workers were divided into 3 categories - consistent daytime workers (CDW), fixed $12 \mathrm{~h}$ day-shift workers (DSW) and fixed $12 \mathrm{~h}$ night-shift workers (NSW). Consistent daytime workers worked in offices from 8:00 a.m. to 5:00 p.m. Shift work schedules on the $24 \mathrm{~h}$ production line were divided according to a fixed 4-team/2-shift plan. Daytime shifts begin at 7:30 a.m. and nighttime shifts at 7:30 p.m. Each shift involved 2 work days followed by 2 rest days. Shift workers did their job in cleanrooms where the environment was controlled to eliminate all dust and kept within consistent as well as narrow limits of humidity $(55 \pm 5 \%)$, and consistent lighting level beyond 1000 lux. Workers needed to wear specific caps, clothes, masks, and shoes. They were required to pass through an air shower gate when entering the cleanroom. Workers were assigned 
to work either fixed $12 \mathrm{~h}$ day-shifts or fixed $12 \mathrm{~h}$ nightshifts at the beginning of employment.

\section{Outcomes}

In this study, the glasses-corrected visual acuity (c-VA) of both eyes $>1.2$ [12] was defined as a good c-VA. The c-VA of the better eye $<0.8$ was defined as an inadequate c-VA $[9,13]$ and c-VA of the better eye $<0.6$ was defined as a low c-VA [13].

\section{Covariates}

According to metabolic syndrome (MetS) criteria, abnormalities of health check-up results were marked if the subjects had any of the following risk determinants [14]:

- central obesity - waist circumference $\geq 90 \mathrm{~cm}$ in men and $\geq 80 \mathrm{~cm}$ in women;

- elevated blood pressure - systolic blood pressure $(\mathrm{SBP}) \geq 130 \mathrm{~mm} \mathrm{Hg}$ or diastolic blood pressure (DBP) $\geq 85 \mathrm{~mm} \mathrm{Hg}$;

- hyperglycemia - fasting sugar $\geq 100 \mathrm{mg} / \mathrm{dl}$;

- hypertriglyceridemia - triglycerides $\geq 150 \mathrm{mg} / \mathrm{dl}$;

- hypo-HDL cholesterolemia - HDL $<40 \mathrm{mg} / \mathrm{dl}$ in men and $<50 \mathrm{mg} / \mathrm{dl}$ in women.
Data of duration of employment was obtained from administrative records and high educational attainment was defined as bachelor's degree or above.

\section{Statistical Analysis}

Baseline characteristics and abnormal rates among CDW, DSW and NSW were compared using the ANOVA test and the $\mathrm{Chi}^{2}$ test for continual and categorical variables as appropriate. Multivariate logistic regression was employed to estimate the adjusted odds ratio $\left(\mathrm{OR}_{\mathrm{a}}\right)$ and $95 \%$ confidence intervals (CI) of risk factors were used for evaluating good c-VA and inadequate c-VA, under adjustments for gender, age, each MetS component and occupational factors. A p-value $<0.05$ was considered statistically significant.

\section{RESULTS}

As shown in the Table 1, the mean age for this sample population was 34.7 years old (standard deviation $(\mathrm{SD})=$ 5.4 years), the mean value of c-VA was $1.1(\mathrm{SD}=0.3)$ for right eye and 1.1 ( $\mathrm{SD}=0.2$ ) for left eye. The overall prevalence rates of inadequate, low and good c-VAs were $4.8 \%, 1.6 \%$ and $32.2 \%$, respectively.

Table 1. Characteristics of study groups - employees with varied work schedules in an electronics manufacturing company

\begin{tabular}{|c|c|c|c|c|c|}
\hline \multirow{2}{*}{ Variable } & \multicolumn{4}{|c|}{ Study groups } & \multirow{2}{*}{$\mathrm{p}^{\mathrm{a}}$} \\
\hline & total & CDW & DSW & NSW & \\
\hline Respondents [n (\%)] & $8280(100.0)$ & $3884(46.9)$ & $2517(30.4)$ & $1879(22.7)$ & $<0.01$ \\
\hline male $[\mathrm{n}(\%)]$ & $5182(62.6)$ & 2745 (70.7) & $1219(48.4)$ & $1218(64.8)$ & $<0.01$ \\
\hline female $[\mathrm{n}(\%)]$ & $3098(37.4)$ & $1139(29.3)$ & $1298(51.6)$ & $661(35.2)$ & $<0.01$ \\
\hline Age [years] $(\mathrm{M} \pm \mathrm{SD})$ & $34.7 \pm 5.4$ & $35.1 \pm 5.3$ & $34.6 \pm 5.5$ & $34.0 \pm 5.4$ & $<0.01$ \\
\hline Seniority [years] $(\mathrm{M} \pm \mathrm{SD})$ & $6.9 \pm 4.3$ & $7.1 \pm 4.2$ & $7.1 \pm 4.3$ & $6.0 \pm 4.3$ & $<0.01$ \\
\hline Waist $[\mathrm{cm}](\mathrm{M} \pm \mathrm{SD})$ & $81.1 \pm 11.3$ & $81.9 \pm 10.5$ & $79.5 \pm 11.6$ & $81.7 \pm 12.0$ & $<0.01$ \\
\hline \multicolumn{6}{|l|}{ Blood pressure $[\mathrm{mm} \mathrm{Hg}](\mathrm{M} \pm \mathrm{SD})$} \\
\hline systolic & $122.1 \pm 14.5$ & $122.1 \pm 14.5$ & $120.7 \pm 14.6$ & $124.1 \pm 14.0$ & $<0.01$ \\
\hline diastolic & $76.0 \pm 11.0$ & $77.2 \pm 10.5$ & $74.1 \pm 11.3$ & $75.9 \pm 11.4$ & $<0.01$ \\
\hline Fasting blood sugar $[\mathrm{mg} / \mathrm{dl}](\mathrm{M} \pm \mathrm{SD})$ & $87.2 \pm 17.7$ & $82.1 \pm 13.0$ & $91.4 \pm 17.8$ & $92.3 \pm 22.3$ & $<0.01$ \\
\hline Triglyceride [mg/dl] $(\mathrm{M} \pm \mathrm{SD})$ & $119.8 \pm 97.4$ & $117.5 \pm 95.6$ & $119.5 \pm 101.1$ & $125.3 \pm 95.7$ & 0.02 \\
\hline
\end{tabular}


Table 1. Characteristics of study groups - employees with varied work schedules in an electronics manufacturing company - cont.

\begin{tabular}{|c|c|c|c|c|c|}
\hline \multirow{2}{*}{ Variable } & \multicolumn{4}{|c|}{ Study groups } & \multirow{2}{*}{$\mathrm{p}^{\mathrm{a}}$} \\
\hline & total & $\mathrm{CDW}$ & DSW & NSW & \\
\hline HDL cholesterol [mg/dl] $(\mathrm{M} \pm \mathrm{SD})$ & $56.5 \pm 13.9$ & $57.6 \pm 14.4$ & $56.3 \pm 13.8$ & $54.6 \pm 12.8$ & $<0.01$ \\
\hline \multicolumn{6}{|l|}{ Corrected visual acuity } \\
\hline left $(\mathrm{M} \pm \mathrm{SD})$ & $1.07 \pm 0.25$ & $1.12 \pm 0.24$ & $1.02 \pm 0.24$ & $1.01 \pm 0.25$ & $<0.01$ \\
\hline right $(\mathrm{M} \pm \mathrm{SD})$ & $1.05 \pm 0.26$ & $1.11 \pm 0.25$ & $1.00 \pm 0.25$ & $0.99 \pm 0.25$ & $<0.01$ \\
\hline Hyperglycemia $[\mathrm{n}(\%)]$ & $1351(16.3)$ & $216(5.6)$ & $619(24.6)$ & $516(27.5)$ & $<0.01$ \\
\hline Hypertriglyceridemia [n (\%)] & $1886(22.8)$ & $855(22.0)$ & $548(21.8)$ & $483(25.7)$ & $<0.01$ \\
\hline Hypo-HDL cholesterol [n (\%)] & $1100(13.3)$ & $382(9.8)$ & $439(17.4)$ & $279(14.8)$ & $<0.01$ \\
\hline Elevated blood pressure $[\mathrm{n}(\%)]$ & $2886(34.9)$ & $1354(34.9)$ & $776(30.8)$ & $756(40.2)$ & $<0.01$ \\
\hline Central obesity $[\mathrm{n}(\%)]$ & $2351(28.4)$ & $1043(26.9)$ & $725(28.8)$ & $583(31.0)$ & $<0.01$ \\
\hline Metabolic syndrome [n (\%)] & $1166(14.1)$ & $413(10.6)$ & $392(15.6)$ & $361(19.2)$ & $<0.01$ \\
\hline \multicolumn{6}{|l|}{ Visual acuity $[\mathrm{n}(\%)]$} \\
\hline good & $2676(32.3)$ & $1649(42.5)$ & $631(25.1)$ & $396(21.1)$ & $<0.01$ \\
\hline inadequate & $398(4.8)$ & $100(2.6)$ & $155(6.2)$ & $143(7.6)$ & $<0.01$ \\
\hline low & $135(1.6)$ & $34(0.9)$ & $50(2.0)$ & $51(2.7)$ & $<0.01$ \\
\hline Highest educational level $\geq$ bachelor's degree & $4934(59.6)$ & $3469(89.3)$ & $844(33.5)$ & $621(33.0)$ & $<0.01$ \\
\hline \multicolumn{6}{|c|}{$\begin{array}{l}\text { M - mean; SD - standard deviation. } \\
\text { HDL - high density lipoprotein. } \\
\text { Hyperglycemia - fasting glucose } \geq 100 \mathrm{mg} / \mathrm{dl} \text {. } \\
\text { Hypertriglyceridemia - triglyceride } \geq 150 \mathrm{mg} / \mathrm{dl} \text {. } \\
\text { Hypo-HDL cholesterol = HDL }<50 \text { in female or }<40 \text { in male. } \\
\text { Elevated blood pressure - systolic blood pressure (SBP) } \geq 130 \mathrm{~mm} \mathrm{Hg} \text { or diastolic pressure (DBP) } \geq 85 \mathrm{~mm} \mathrm{Hg} \text {. } \\
\text { Central obesity - waist circumference } \geq 80 \mathrm{~cm} \text { in female or } \geq 90 \mathrm{~cm} \text { in male. } \\
\text { CDW - consistent daytime workers ( }(8 \mathrm{~h} / \text { day); DSW - day-shift workers (12 h/day); NSW - night-shift workers ( } 12 \mathrm{~h} / \text { night). } \\
\text { a ANOVA was conducted for numeral variables, using Tukev's test. Chi test was conducted for categorical variables among }\end{array}$} \\
\hline
\end{tabular}

The distribution rates of CDW, DSW and NSW were $46.9 \%, 30.4 \%$ and $22.7 \%$, respectively. The Table 1 also shows the personal, occupational data, metabolic health risk factors and c-VA among the 3 subgroups. As it can be seen, CDW had significantly more favorable c-VA measurements and a higher rate of good c-VA than the shift workers did (CDW, DSW and NSW: 42.5\%, 25.1\% and $21.1 \%$, respectively, $p=0.047$ ). Night-shift workers had a significantly higher rate of inadequate c-VA (CDW, DSW and NSW: $2.6 \%, 6.2 \%$, and $7.6 \%$, respectively, $p=0.03$ ), and a significantly higher rate of low c-VA than the day- time workers did (CDW, DSW and NSW: $0.9 \%, 2 \%$ and $2.7 \%$, respectively, $\mathrm{p}=0.03$ ).

Although NSW were the youngest among all 3 subgroups, they had significantly higher rates for metabolic abnormalities than the daytime workers (CDW and DSW) did. Differences of corrected visual acuities between workers with varied work schedules are demonstrated in the Table 2. The CDW significantly had the best measures of c-VA among 3 subgroups.

The decreasing trends of c-VA with increasing age for both daytime and nighttime workers can be seen in the 
Table 2. Differences of corrected visual acuities amongst employees with varied work schedules in an electronics manufacturing company

\begin{tabular}{lcc}
\hline \multirow{2}{*}{ Variable } & \multicolumn{2}{c}{ Corrected visual acuity } \\
\cline { 2 - 3 } & left side & right side \\
\hline M & 1.07 & 1.05 \\
RMSE & 0.24 & 0.25 \\
df & 2.00 & 2.00 \\
Sum of squares & 25.08 & 28.77 \\
MS & 12.54 & 14.38 \\
F & 212.98 & 227.86 \\
p & $<0.01$ & $<.01$ \\
CDW vs. DSW [MD (95\% CI)] & $0.10(0.09-0.12)$ & $0.12(0.1-0.13)$ \\
CDW vs. NSW [MD (95\% CI)] & $0.12(0.1-0.13)$ & $0.12(0.1-0.14)$ \\
DSW vs. NSW [MD (95\% CI)] & $0.01(-0.01-0.03)$ & $0.004(-0.01-0.02)$ \\
\hline
\end{tabular}

M - mean; RMSE - root mean square error; $\mathrm{df}$ - degrees of freedom; MS - mean square; MD - mean difference; CI - confidence interval. CDW - consistent daytime workers ( $8 \mathrm{~h} /$ day); DSW - day-shift workers (12 h/day); NSW - night-shift workers (12 h/night).

Figure 1. Particularly, in line with the aging process, the downward trends revealed that nighttime workers reached the inadequate (better eye c-VA $<0.8$ ) or low visual acuity (better eye $\mathrm{c}-\mathrm{VA}<0.6$ ) sooner than daytime workers did.
In the multivariate analysis, after adjusting for potential confounding variables, NSW were found to have a significantly unfavorable c-VA (Table 3). Night-shift workers had the $\mathrm{OR}_{\mathrm{a}}=2.7,95 \% \mathrm{CI}: 2.0-3.6$, vs. $\mathrm{CDW}$ for

Table 3. Multivariate analysis for adjusted odds ratio of decreased visual acuity among employees with varied work schedules in an electronics manufacturing company

\begin{tabular}{lcrlrrr}
\hline \multirow{2}{*}{\multicolumn{1}{c}{ Variable }} & \multicolumn{9}{c}{ Visual acuity } \\
\cline { 2 - 7 } & \multicolumn{2}{c}{ inadequate } & \multicolumn{1}{c}{ low } & good \\
\cline { 2 - 7 } & $\mathrm{OR}_{\mathrm{a}}(95 \% \mathrm{CI})$ & $\mathrm{p}$ & $\mathrm{OR}_{\mathrm{a}}(95 \% \mathrm{CI})$ & $\mathrm{p}$ & $\mathrm{OR}_{\mathrm{a}}(95 \% \mathrm{CI})$ & $\mathrm{p}$ \\
\hline Female vs. male gender & $1.3(1.1-1.7)$ & 0.01 & $1.3(0.9-1.9)$ & 0.15 & $0.7(0.6-0.8)$ & $<0.01$ \\
DSW vs. CDW & $2.0(1.5-2.7)$ & $<0.01$ & $1.7(1.02-2.9)$ & 0.04 & $0.6(0.5-0.6)$ & $<0.01$ \\
NSW vs. CDW & $2.7(2.0-3.6)$ & $<0.01$ & $2.6(1.5-4.4)$ & $<0.01$ & $0.4(0.4-0.5)$ & $<0.01$ \\
Age [years] & $1.1(1.05-1.1)$ & $<0.01$ & $1.1(1.02-1.1)$ & $<0.01$ & $0.98(0.971-0.995)<0.01$ \\
Seniority [years] & $0.97(0.9-0.99)$ & 0.02 & $1.0(0.95-1.1)$ & 0.94 & $1.0(1.004-1.03)$ & 0.02 \\
Central obesity vs. normal & $1.1(0.8-1.4)$ & 0.57 & $1.4(0.96-2.1)$ & 0.08 & $1.0(0.9-1.1)$ & 0.65 \\
Hyperglycemia vs. normal & $1.4(1.1-1.8)$ & $<0.01$ & $1.7(1.2-2.5)$ & 0.01 & $0.6(0.5-0.7)$ & $<0.01$ \\
Elevated blood pressure vs. normal & $0.8(0.7-1.1)$ & 0.15 & $0.7(0.5-1.0)$ & 0.07 & $1.0(0.9-1.1)$ & 0.82 \\
Hypo-HDL cholesterol vs. normal & $1.2(0.9-1.6)$ & 0.19 & $1.0(0.7-1.7)$ & 0.87 & $0.9(0.7-1.01)$ & 0.07 \\
Hypertriglyceridemia vs. normal & $1.1(0.8-1.4)$ & 0.53 & $1.1(0.7-1.7)$ & 0.70 & $0.9(0.8-0.99)$ & 0.04 \\
High educational level vs. < bachelor degree & $0.9(0.7-1.1)$ & 0.32 & $0.8(0.5-1.3)$ & 0.43 & $1.1(0.9-1.2)$ & 0.29 \\
\hline
\end{tabular}

$\mathrm{OR}_{\mathrm{a}}$ - adjusted odds ratio for age, gender, education, job types, duration of work and metabolic components.

Other abbreviations as in Table 1 and 2. 


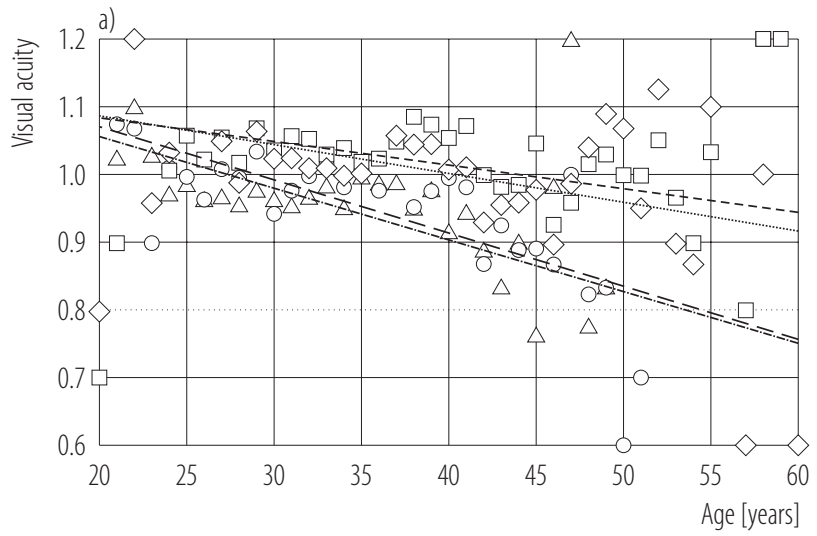

................. daytime workers' $c-V A-(R)$

- - - $\square-$ - - daytime workers' $\mathrm{c}-\mathrm{VA}-(\mathrm{L})$

$--\triangle-\cdots$ nighttime workers' $c-V A-(R)$

$-\infty-$ - nighttime workers' $C-V A-(L)$

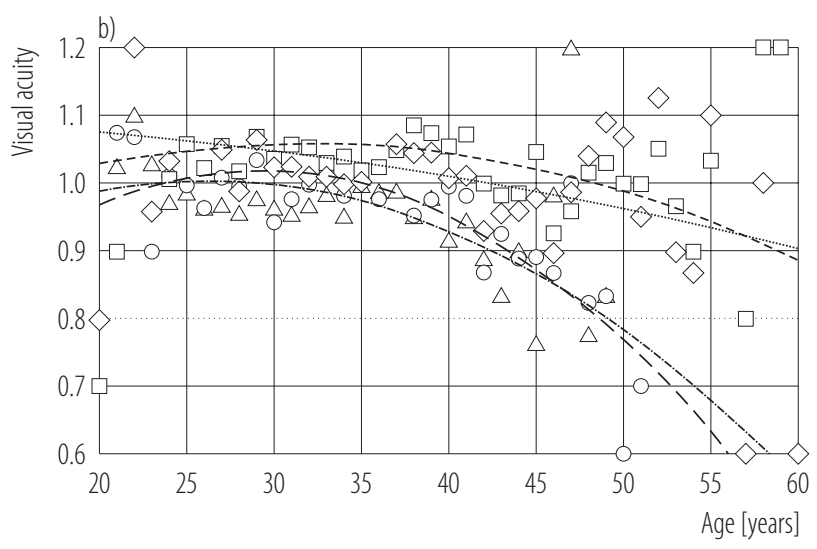

$\cdots . . . . \cdots \cdots . . .$. daytime workers' $C-V A-(R)$

- - - $\square-$ - - daytime workers' $\mathrm{C}-\mathrm{VA}-(\mathrm{L})$

-.-- $\triangle$-.- nighttime workers' $c-V A-(R)$

$-\infty-$ - nighttime workers' $c-V A-(L)$

Daytime workers - consistent daytime workers (CDW, 8 h/day)

and day-shift workers (DSW, 12 h/day).

Nighttime workers - night-shift workers (NSW, 12 h/night).

c-VA - corrected visual acuity; $\mathrm{R}$ - right side; L - left side.

Fig. 1. Trends of visual acuity distributions: a) linear and b) quadratic - according to age of employees with varied work schedules in an electronics manufacturing company

inadequate c-VA; $\mathrm{OR}_{\mathrm{a}}=2.6,95 \% \mathrm{CI}: 1.5-4.4$, vs. $\mathrm{CDW}$ for low c-VA; and $\mathrm{OR}_{\mathrm{a}}=0.4,95 \%$ CI: $0.4-0.5$, vs. CDW for good c-VA. Besides, analysis results also showed that DSW $\left(\mathrm{OR}_{\mathrm{a}}=2,95 \% \mathrm{CI}: 2.0-3.6\right.$, vs. CDW $)$, elevated blood sugar $\left(\mathrm{OR}_{\mathrm{a}}=1.4,95 \% \mathrm{CI}: 1.1-1.8\right)$ and female gender $\left(\mathrm{OR}_{\mathrm{a}}=1.3,95 \% \mathrm{CI}\right.$ : $\left.1.1-1.7\right)$ were independently associated with inadequate c-VA. Similarly, DSW
Table 4. Head to head multivariate analysis of visual acuity among employees with different work schedules

(NSW vs. DSW) in an electronics manufacturing company

\begin{tabular}{lcr}
\hline \multicolumn{1}{c}{ Visual acuity } & $\mathrm{OR}_{\mathrm{a}}(95 \% \mathrm{CI})$ & $\mathrm{p}$ \\
\hline Inadequate & $1.3(1.010-1.7)$ & 0.040 \\
Low & $1.5(1.002-2.3)$ & 0.048 \\
Good & $0.8(0.700-0.9)$ & $<0.010$ \\
\hline
\end{tabular}

NSW - night-shift workers (12 h/night); DSW - day-shift workers (12 h/day).

Abbreviations as in Table 2 and 3.

$\left(\mathrm{OR}_{\mathrm{a}}=1.7,95 \%\right.$ CI: $1.02-2.9$, vs. $\left.\mathrm{CDW}\right)$ and elevated blood sugar $\left(\mathrm{OR}_{\mathrm{a}}=1.7,95 \% \mathrm{CI}: 1.2-2.5\right)$ were independently associated with low c-VA.

Finally, NSW $\left(\mathrm{OR}_{\mathrm{a}}=0.4,95 \%\right.$ CI: $0.4-0.5$ vs. CDW $)$, DSW $\left(\mathrm{OR}_{\mathrm{a}}=0.6,95 \% \mathrm{CI}: 0.5-0.6\right.$ vs. CDW $)$, hyperglycemia $\left(\mathrm{OR}_{\mathrm{a}}=0.6,95 \% \mathrm{CI}: 0.5-0.7\right)$, female gender $\left(\mathrm{OR}_{\mathrm{a}}=0.7,95 \% \mathrm{CI}: 0.6-0.8\right)$ and hypertriglyceridemia $\left(\mathrm{OR}_{\mathrm{a}}=0.9,95 \%\right.$ CI: 0.8-0.99) were the inverse factor for workers possessing a good c-VA.

For all the shift workers in the head to head analysis, comparing between with and without nighttime work exposure (Table 4), significantly unfavorable c-VA was found among NSW, who had the $\mathrm{OR}_{\mathrm{a}}=1.3,95 \%$ CI: 1.01-1.7, vs. DSW for inadequate c-VA, the $\mathrm{OR}_{\mathrm{a}}=1.5,95 \% \mathrm{CI}$ : 1.002-2.3, vs. DSW for low c-VA; and the $\mathrm{OR}_{\mathrm{a}}=0.8,95 \% \mathrm{CI}$ : 0.70.9 , vs. DSW for good c-VA.

\section{DISCUSSION}

To the best of our knowledge, this is the first large scale study illustrating that night workers have significantly lower visual acuity as compared to the daytime employees (CDW and DSW). Findings from this worker population could contribute to health policy development in similar workplaces. Additionally in this study, aging, elevated blood sugar and female gender were also found to be associated with inferior visual acuities. In terms of workplace health promotion and work fitness [15], visual health protection for the susceptible workers are desirable [16]. 
In this study, night-shift workers had significantly inferior c-VAs compared with the daytime workers. The workers exposed to night-shift work were also markedly less likely to process good visual acuity (Tables 1,3 and 4). Symptomatically, dry eyes syndrome and visual fatigue, as reported in the research of night jobs, disturbed sleep and cleanroom [4,5,17], are associated with reduced visual function [18].

Shift workers, especially those working long hours, should be provided with appropriate resting periods to help recover from eye fatigue. Biopathologically, low visual acuity is highly correlated with adverse retina health condition [19], which may be affected by shift-works [7,8]. Since chronic circadian rhythm disruption may induce inflammatory reactions, a probable biological explanation for the reduced visual acuity of nighttime workers might be the inflammatory lesions on retina [20,21]. Melatonin, a circadian rhythm hormone, was shown to improve visual function via anti-inflammatory effects [22]. It will be interesting to test whether anti-inflammatory supplements may improve visual health among nighttime workers.

The prevalence of hyperglycemia in this young middle-aged worker population was $16.3 \%$ (Table 1); and high blood sugar is found to be associated with an increased risk of poor visual acuity among workers (Table 3). Hyperglycemia is a predisposing factor for retinal damage [23], successful control of hyperglycemia may slow down progression of retinopathy and improve visual acuity [24]. Considering visual health, blood sugar monitoring and control ought to be an important item in a workplace health promotion project.

This study found that with the increasing age, nighttime workers reached the outcome of inadequate or low visual acuity sooner than daytime workers (CDW and DSW) did (Figure 1). Although NSW were the youngest among all 3 subgroups, they did not have the better visual acuity (Table 1-4). A sharp decline in visual acuity of the nighttime workers aged over 40-45 years old was consistent with previous findings from observations of shift workers in many health aspects [25]. Age-specific decline in visual acuity had been confirmed [26,27] and circadian disruption accelerating the aging process was highly plausible $[28,29]$. In terms of occupational health and safety [4], visual function decline should be an important concern for the aging nighttime workforce.

Regarding the gender-related differences, these findings are similar to those of previous large-scale studies [30,31], showing that women employees have higher rates of decreased visual acuity than men employees do. Meanwhile, the relationship between sex hormone changes and visual function variations had been reported in healthy individuals [32]. Thus, individualized strategies in the visual health protection for both genders might be required in the future.

The main goal of large scale workplace health surveillance is usually for screening rather than for definite diagnosis. Hence, some potential limitations of our analysis need to be considered. Firstly, the precise diagnosis of visual deficiencies requires further evaluation from ophthalmologists. Secondly, these screening results did not necessarily represent the best-spectacle corrected visual acuity of workers, caution should be taken when applying our conclusions to the general population. Eye lens and fundus conditions, visual accommodation, intraocular pressure and other contributing factors should be also evaluated longitudinally in future investigations of nighttime workers. Certainly, more precise researches for mechanisms, interactions of each risk factor that influencing the visual acuity of night-shift workers must be conducted in the future.

\section{CONCLUSIONS}

Nighttime work is moderately associated with compromised visual acuity among the employees of this large electronics manufacturing company. Since atypical schedules are common in modern workplaces, we suggest that, when arranging long-term atypical work schedules, the employers and managers should evaluate and promote the visual health of nighttime workers. 


\section{REFERENCES}

1. Wiechmann AF, Summers JA. Circadian rhythms in the eye: The physiological significance of melatonin receptors in ocular tissues. Prog Retin Eye Res. 2008;27:137-60, https://doi. org/10.1016/j.preteyeres.2007.10.001.

2. Richter HG, Torres-Farfan C, Rojas-Garcia PP, Campino C, Torrealba F, Seron-Ferre M. The circadian timing system: Making sense of day/night gene expression. Biol Res. 2004; 37:11-28, https://doi.org/10.4067/S0716-97602004000100003.

3. Wang NL, Hao J, Zhen Y, Liu JH, Li SZ, Wang H, et al. A population-based investigation of circadian rhythm of intraocular pressure in habitual position among healthy subjects: The Handan Eye Study. J Glaucoma. 2016;25(7):584-9, https://doi.org/10.1097/IJG.0000000000000351.

4. Lee ML, Howard ME, Horrey WJ, Liang Y, Anderson C, Shreeve MS, et al. High risk of near-crash driving events following night-shift work. Proc Natl Acad Sci U S A. 2016;113:176-81, https://doi.org/10.1073/pnas.1510383112.

5. Dehghan H, Azmoon H, Souri S, Akbari J. The effects of state anxiety and thermal comfort on sleep quality and eye fatigue in shift work nurses. J Educ Health Promot. 2014;3:72.

6. Kara N, Yilmaz T. Twenty-four hour pattern of intraocular pressure and ocular perfusion pressure in night shift workers. Semin Ophthalmol. 2015;30:188-92, https://doi.org/10.3109/ 08820538.2013.839715.

7. Brodie FL, Charlson ES, Aleman TS, Salvo RT, Gewaily DY, Lau MK, et al. Obstructive sleep apnea and central serous chorioretinopathy. Retina. 2015;35:238-43, https:/doi.org/ 10.1097/IAE.0000000000000326.

8. Bousquet E, Dhundass M, Lehmann M, Rothschild PR, Bayon V, Leger D, et al. Shift work: A risk factor for central serous chorioretinopathy. Am J Ophthalmol. 2016;165:23-8, https://doi.org/10.1016/j.ajo.2016.02.012.

9. Laws and Regulations Database of The Republic of China [Internet]. The Database; 2017 [cited 2014 May 6]. Occupational Safety and Health Act, article 6. Available from: http:// laws.mol.gov.tw/Eng/FLAWDAT0201.aspx?lsid=FL015013.
10. Laws and Regulations Database of The Republic of China [Internet]. The Database; 2017 [cited 2016 May 12]. Regulations of Labor Insurance Health Examination for Prevention of Occupational Disease, 2015. Available from: http://laws. mol.gov.tw/Eng/FLAWDAT0202.aspx?1sid=FL014994.

11. Curnyn KM, Kaufman LM. The eye examination in the pediatrician's office. Pediatr Clin North Am. 2003;50:25-40, https://doi.org/10.1016/S0031-3955(02)00141-4.

12. Nomura H, Ando F, Niino N, Shimokata H, Miyake Y. Age-related change in contrast sensitivity among Japanese adults. Jpn J Ophthalmol. 2003;47:299-303, https://doi.org/ 10.1016/S0021-5155(03)00011-X.

13. Laws and Regulations Database of The Republic of China [Internet]. The Database; 2017 [cited 2016 May 12]. [Regulations of the labor health protection]. Available from: http://law.moj.gov.tw/LawClass/LawAllIf.aspx?PCode= N0060022. Chinese.

14. Chang JH, Huang PT, Lin YK, Lin CE, Lin CM, Shieh YH, et al. Association between sleep duration and sleep quality, and metabolic syndrome in Taiwanese police officers. Int J Occup Med Environ Health. 2015;28:1011-23, https://doi. org/10.13075/ijomeh.1896.00359.

15. Zevallos J, Hulshof CT, Mutsaerts T, Sluiter JK. Outcomes of seafarer work fitness qualifications in the Netherlands. Occup Med (Lond). 2014;64:267-70, https://doi.org/10.1093/ occmed/kqu020.

16. Gowan NJ. Setting visual pre-placement testing in a technology manufacturing environment. Work. 2014;47:371-9, https://doi.org/10.3233/WOR-131772.

17. Su SB, Wang BJ, Tai C, Chang HF, Guo HR. Higher prevalence of dry symptoms in skin, eyes, nose and throat among workers in clean rooms with moderate humidity. J Occup Health. 2009;51:364-9, https://doi.org/10.1539/joh.Q8002.

18. Sharma A, Hindman HB. Aging: A predisposition to dry eyes. J Ophthalmol. 2014;2014:781683, https://doi.org/10. 1155/2014/781683.

19. Sun JK, Lin MM, Lammer J, Prager S, Sarangi R, Silva PS, et al. Disorganization of the retinal inner layers as 
a predictor of visual acuity in eyes with center-involved diabetic macular edema. JAMA Ophthalmol. 2014;132:130916, https://doi.org/10.1001/jamaophthalmol.2014.2350.

20. Lien EL, Hammond BR. Nutritional influences on visual development and function. Prog Retin Eye Res. 2011;30: 188-203, https://doi.org/10.1016/j.preteyeres.2011.01.001.

21. Yoshida N, Ikeda Y, Notomi S, Ishikawa K, Murakami Y, Hisatomi T, et al. Clinical evidence of sustained chronic inflammatory reaction in retinitis pigmentosa. Ophthalmology. 2013;120:100-5, https://doi.org/10.1016/j.ophtha.2012.07.006.

22. Gramajo AL, Marquez GE, Torres VE, Juarez CP, Rosenstein RE, Luna JD, et al. Therapeutic benefit of melatonin in refractory central serous chorioretinopathy. Eye (Lond). 2015;29:1036-45, https://doi.org/10.1038/eye.2015.104.

23. Xin Z, Yuan MX, Li HX, Hua L, Feng JP, Shi J, et al. Evaluation for fasting and 2-hour glucose and HbAlc for diagnosing diabetes based on prevalence of retinopathy in a Chinese population. PLoS One. 2012;7:e40610, https://doi. org/10.1371/journal.pone.0040610.

24. Chew EY, Davis MD, Danis RP, Lovato JF, Perdue LH, Greven C, et al. The effects of medical management on the progression of diabetic retinopathy in persons with type $2 \mathrm{di}$ abetes: The Action to Control Cardiovascular Risk in Diabetes (ACCORD) eye study. Ophthalmology. 2014;121: 2443-51, https://doi.org/10.1016/j.ophtha.2014.07.019.

25. Koller M. Health risks related to shift work. An example of time-contingent effects of long-term stress. Int Arch Occup Environ Health. 1983;53:59-75, https://doi.org/10.1007/ BF00406178.
26. Wolska A, Sawicki D. Evaluation of discomfort glare in the 50+ elderly: Experimental study. Int J Occup Med Environ Health. 2014;27:444-59, https://doi.org/10.2478/s13382-0140257-9.

27. Sjostrand J, Laatikainen L, Hirvela H, Popovic Z, Jonsson R. The decline in visual acuity in elderly people with healthy eyes or eyes with early age-related maculopathy in two Scandinavian population samples. Acta Ophthalmol. 2011;89: 116-23, https://doi.org/10.1111/j.1755-3768.2009.01653.x.

28. Orozco-Solis R, Sassone-Corsi P. Circadian clock: Linking epigenetics to aging. Curr Opin Genet Dev. 2014;26:66-72, https://doi.org/10.1016/j.gde.2014.06.003.

29. Mate I, Madrid JA, de la Fuente M. Chronobiology of the neuroimmunoendocrine system and aging. Curr Pharm Des. 2014;20:4642-55, https://doi.org/10.2174/1381612820666140 130201131.

30. Xu L, You QS, Wang YX, Jonas JB. Associations between gender, ocular parameters and diseases: The Beijing Eye Study. Ophthalmic Res. 2011;45:197-203, https://doi.org/ 10.1159/000321522.

31. Wu JF, Bi HS, Wang SM, Hu YY, Wu H, Sun W, et al. Refractive error, visual acuity and causes of vision loss in children in Shandong, China. The Shandong Children Eye Study. PLoS One. 2013;8:e82763, https://doi.org/10.1371/ journal.pone.0082763.

32. Akar Y, Yucel I, Akar ME, Taskin O, Ozer HO. Menstrual cycle-dependent changes in visual field analysis of healthy women. Ophthalmologica. 2005;219:30-5, https://doi.org/ $10.1159 / 000081780$.

This work is available in Open Access model and licensed under a Creative Commons Attribution-NonCommercial 3.0 Poland License - http://creativecommons.org/ licenses/by-nc/3.0/pl/deed.en. 